\title{
THE PERCEPTIONS OF MORALITY OF SECONDARY SCHOOL LEARNERS: A CROSS-CULTURAL STUDY
}

\author{
J. Coetzee, D.A. Louw \& J.C. Jooste ${ }^{1}$
}

\begin{abstract}
The focus of this research is to determine the perceptions of morality among a group of young South Africans. More specifically, the possible role that gender, culture, lifestyle, religion and sexual practices in these perceptions of morality may play will be investigated. To date, no studies have attempted to measure the youth's perceptions of morality. Consequently, little South African literature is available. While many variables are believed to influence the development and expression of morality, the variables that were measured in this study included gender, culture, lifestyle, sexual experience and religion, as found in literature. Seven schools were involved in this study. They were classified as being high, average and below average with regards to academic performance. After statistical analysis, the variable found to have the greatest influence on the perception of morality was gender. A core finding of this study was that the female learner's responses point towards a higher level of morality than the male learners do. This study also found cultural differences with regard to morality. Frequency of religious practices was also found to have an influence on moral expression. The study also indicated that past sexual experience has an effect on the perception and expression of morality. Lifestyle was not found to be a significant factor in the perception of morality in this study. The results of the research will help to give clearer understanding of the youth's perception of morality, which could then be incorporated into combating immorality, for example, through developing programmes in this regard. For future and especially comparative purposes, the findings of this study could also serve as a base-line measurement of the perceptions of morality among the South African youth, should one wish to determine to what extent these perceptions are static or dynamic.
\end{abstract}

1 Mr. J. Coetzee, Prof. D.A. Louw and Dr. J.C. Jooste, Department of Psychology, University of the Free State, P.O. Box 339, Bloemfontein 9300, South Africa. All correspondence should be addressed to Prof. D.A. Louw, e-mail: louwda.hum @ mail.uovs.ac.za. The authors wish to thank Dr. L. Hoffman for her editorial assistance. 


\section{INTRODUCTION}

The problem of declining morality, ${ }^{2}$ especially among the youth, is an age-old and worldwide issue. This is especially true in South Africa where the ever-decreasing levels of morality affect communities as well as the entire country. For example, the economy is affected due to lowered investor confidence, which is influenced by the high instances of violence and crime. As far as the family is concerned, South Africa is also suffering. For example, more children are becoming orphaned due to HIV/Aids, and many parents have lost children and even entire families to violence. This issue has steadily gained importance in South Africa and has become the focus of national attention as highlighted by the Deputy President, Mr Jacob Zuma, in his address on moral regeneration: "[T] tinuing to plague our communities" (Retrieved from the World Wide Web on 24 February 2002). This viewpoint has steadily been gaining support from various arenas, including religious, educational and political.

As morality is seen as an antipode to the ever-increasing incidence of among others, crime, violence and HIV/Aids (Carlo et al. 1999; Judy \& Nelson 2000), it is essential that the issue of morality in the country be addressed. No planning to address this situation can begin, however, without reliable data. This is especially pertinent in South Africa, as international and frequently irrelevant data often has to be relied on.

\section{FACTORS CONTRIBUTING TO THE DEVE- LOPMENT AND EXPRESSION OF MORALITY}

Morality is not merely a static and theoretical concept, isolated from everyday life, but is influenced and affected by many variables to a greater or lesser degree. While all possible influences need not be

2 Various definitions and viewpoints regarding morality exist. However, it is beyond the scope of this research to give an in-depth discussion on the differing and even contradictory standpoints. For the purpose of this study, morality is defined as the process whereby children learn how to differentiate between right and wrong, which will then direct their behaviours and actions (Vander Zander 1989). 
present simultaneously, each influencing factor, either separately or in conjunction with another, is essential to the degree of morality expressed. Some of the factors found to contribute towards the development and expression of morality are very briefly summarised next:

- Degree of empathy expressed by an individual. Eisenberg (2000) and Bush et al. (2000) found that empathy encouraged moral behaviour and resulted in changes in an individual's attitude towards others. Shelton and McAdams (1990) have stated that by utilising empathy, more moral behaviour can be promoted. Empathy for others appears to contribute towards prosocial moral behaviour.

- Educational environment. According to Levine et al. (2000) and Myyry and Helkama (2001), the fact that education and logical skills are associated with the level of moral reasoning, differences in educational backgrounds can cause differences in level of morality. Eisenberg (1986) also found that differences in educational backgrounds are often responsible for cross-cultural differences in the level of morality between groups. This is especially relevant in South Africa as the standard of education is still not consistent. Hence, disadvantaged learners may be at a disadvantage with regards to moral development.

- Social acceptance. The moral reasoning of adolescents between the ages of 13 and 16 is determined to a large extent by approval or disapproval of others (Eisenberg et al. 1995; Eisenberg et al. 1991). Hence, should moral virtue be the norm for example, breaking away from the norm would be more difficult due to peer pressure, but the inverse also holds true. Should promiscuity, for example, be the norm in an individual's social group, resisting social pressure to conform to the group's norm may prove to be both difficult and unpopular, possibly leading to rejection. Therefore, following group trends may prove to be more prudent in terms of social acceptance.

- Home environment. Wilson and Ramphele (1989) found that the disorganisation of the family, over-crowding and poor living environment play a major role in the development of morality in adolescents. This is especially true in South Africa where historical and psycho-political factors have created a unique situation that 
is conducive to creating a negative home environment. For example, both fathers and mothers often have to leave their families early in the morning and only return late in the evening. This implies very little, if any, parental involvement in their children's lives, making moral education very difficult. On the other hand, Sterponi (2003) has found that informal family discussions on morals can promote moral reasoning. Also in this regard, White and Matawie (2004) found that several facets of both parents' morality significantly predicted adolescents' morality.

- Age. Age is another factor that plays an important role in moral reasoning. Kohlberg is an important figure in the world of psychology due to his work on morality. He proposed that morality and age are related and further contended that age is related to specific stages of moral reasoning. He went on to say that most adolescents and adults function in level two, the conventional level which consists of two stages (stages three and four). Stage three is characterised by the child behaving in such a way so as to be accepted and avoid rejection. In stage four, rules are followed because they are an important source of identity and are viewed as essential for maintaining law and social order. (Kohlberg 1985). As an individual grows older, so that individual will progress and change ways of thinking and reasoning; this too is true for moral reasoning (Branch 2000).

- Culture. Cross-cultural studies by Holmes et al. (1991), Kawanishi (1995) and Pittman et al. (1995) indicate that differences in cultural norms are associated with different expectations for behaviour, attitudes, and emotional expression. These culturally variant expectations will emphasise different aspects of morality. As a result, perceptions of morality, as well as the development of morality, tend to differ between cultures and ethnic groups. Therefore it is not inconceivable that the perceptions of morality between Zulu and Tswana learners for instance may vary.

- Gender. This factor has been linked to individual differences in moral reasoning (Gustavo et al. 1996). To date however, there are still no clear indications as to how much of an influence gender has on moral reasoning (Walker 1991). Eisenberg et al. (1989) have 
theorised that gender differences in moral reasoning are as a result of gender-specific socialisation processes. They further contend that adolescent girls express a higher level of moral reasoning over adolescent boys.

- Religion. Many researchers accept that there is a strong correlation between religion and morality (Duncan 2002; Emerson 1996; Jensen 1997; Schwartz \& Huismans 1995; Van der Ven 2002). Beard (1988) investigated whether religion is related to moral judgement levels. Different religious groups in South Africa were tested. He concluded that religion does indeed have an affect on morality. Furthermore, he found that frequency of religious practice had an impact on the level and expression of morality. Not only is there a strong correlation between religion and morality, but religion directly influences moral development.

To date, very little research has been conducted in South Africa regarding morality, especially regarding the youth. Hence, as already mentioned, the focus of this research is to determine the perceptions of morality among a group of young South Africans. More specifically, the possible role that gender, culture, lifestyle (their perception), religion (practise of) and sexual practices in these perceptions of morality may play will be investigated. The results of the research will help to give clearer understanding of the youth's perception of morality, which could then be incorporated into combating immorality, for example, through developing programmes in this regard. For future and especially comparative purposes, the findings of this study could also serve as a base-line measurement of the perceptions of morality among the South African youth should one wish to determine to what extent these perceptions are static or dynamic.

\section{METHODOLOGY}

\subsection{Participants and instruments used}

The research sample consisted of 340 Grade 10 learners.

Seven schools were involved in this study. They were classified as being high, average and below average with regards to academic performance. Of these schools, three were black schools from Mangaung. 
The remainder of the schools were found in Bloemfontein, of which two were white Afrikaans schools and two were interracial English schools. An age limit of between 12 and 17 years was imposed.

The biographically characteristics of the participants appear in Table 1.

Table 1: Frequency distribution of the biographical variables for the research groups

\begin{tabular}{|l|r|r|}
\hline Biographical variable & N & $\%$ \\
\hline Gender: & 173 & \\
Female & 167 & 50,9 \\
Male & 165 & 49,1 \\
\hline Culture group: & 147 & 48,5 \\
African (Black) & 16 & 43,2 \\
White & 2 & 4,7 \\
Coloured & 10 & 0,6 \\
Indian & & 2,9 \\
Other & 99 & \\
\hline Lifestyle: & 218 & 29,3 \\
Better than most & 21 & 64,5 \\
Same as most & & 6,2 \\
\hline Worse than most & 202 & 66,4 \\
\hline Religion (practice): & 34 & 11,2 \\
Weekly or more & 38 & 12,5 \\
Monthly & 30 & 9,9 \\
\hline Only on religious occasions & & \\
Seldom & 98 & 29,1 \\
\hline Sexually active: & 239 & 70,9 \\
Yes & & \\
No & & \\
\hline
\end{tabular}

It is evident that the number of male and female respondents is approximately equal. This is due to the sampling method used. White and black respondents were also roughly equally divided. This can be contributed to the sampling procedure to include an equal number of black and white learners. Most of the participants maintained an average lifestyle with nearly one third describing their lifestyle as above 
average. Religion was measured according to frequency of practice. According to this criterion, two thirds reported practising their religion weekly or more. An interesting finding was that approximately $30 \%$ of the participants reported being sexually active.

The measuring instruments used in this study:

- A self-compiled biographical questionnaire based on variables found in the literature. This questionnaire was used to obtain information regarding gender, race, religion, socio-economic status and sexual practices.

- The Moral Behaviour Scale of Crissman, Rettig and Pasamanick as found in Robinson et al. (1991). The scale consists of examples of different behaviours which are presented to learners who then judge it to be either moral or immoral behaviour.

- The Morally Debatable Behaviour Scale of Harding and Philips as found in Robinson et al. (1991). This questionnaire consists of morally debatable behaviours and requires respondents to indicate which contemporary behaviours can be justified and which cannot.

According to Robinson et al. (1991) both morality questionnaires meet the necessary psychometric requirements for reliability and validity. Unfortunately no South African research utilising these measuring instruments could be traced.

As the questionnaires were only in English, for many of the learners this meant completing the questionnaires in either a second or even a third language. Therefore each question was explained to the learners, often making use of relevant examples. Learners were asked to complete all three questionnaires as honestly as possible, and without omitting any items.

\subsection{Analysis of data}

From Table 1 it is apparent that certain biographical variables (e.g. cultural group) contain too few participants per cell to comply with criteria needed for reliable statistical analysis. For one of the biographical variables, namely religion, the responses "monthly", "occasionally", and "seldom" have been grouped together. In this case there 
are therefore two categories, namely those who indicated they practised their religion weekly or more $(n=202)$, and those who indicated they practise their religion monthly or less $(n=102)$. With regards to culture and lifestyle, it was not sensible to group some of the categories together, and in this case, categories with very few persons were left out. With regard to culture the last three groups were left out so that only African and white learners were used. Regarding lifestyle, the respondents in the last category ("worse than most") were left out and only the "better than most" and the "same as most" categories were used. By following this method, it is obvious that all five biographical variables consist of two categories (dichotomies).

For the purposes of this study, only 20 of the 50 items in the case of the Moral Behaviour Scale (MBS) but all 22 in the case of the Morally Debatable Behaviour Scale were used. This was done so that the volume of data did not exceed the limits of this study. The 20 chosen were representative of the moral issues covered in the scale. In this case, a large number of dependent variables were included, and so it was decided not to use all 42 items at once for the different subgroups (according to the biographical variables) comparisons. The items were first used for the Moral Behaviour Scale items and then the Morally Debatable Behaviours Scale items. According to Tabachnick and Fidell (1989), Hotelling's $\mathrm{T}^{2}$ test is the appropriate statistical technique to be used in such a case. With the $\mathrm{T}^{2}$ test, the means of the vectors for the dependent variables are simultaneously compared with each other in order to limit the occurrence of a Type 1 error. In the case of a significant T2 value being found, a post hoc $t$-test analysis will be performed in order to determine in which dependent variable the significant difference in average for the determined two subgroups occurs.

In order to address the practical importance of statistically significant results that will be found in the course of this investigation, the practical significance of the results will also be investigated. Effect size will be the measure of practical significance. The calculation of the practical significance of the Hotelling $\mathrm{T}^{2}$ value will be compared with the means of vectors, and the effect size will be calculated as follows (Steyn 1999): 


$$
f=\mathrm{T} / \sqrt{ } \mathrm{N}
$$

In order to interpret the effect sizes, the following guidelines can be used:

$$
\begin{array}{lll}
f=0,1 & : & \text { small effect } \\
f=0,25 & : & \text { medium effect } \\
f=0,4 & : & \text { large effect }
\end{array}
$$

In the event of a significant $\mathrm{T}^{2}$ value with a large practical significance being found, the analysis will be followed up with a post hoc $t$-test. With regards to the aforementioned test, the adjusted effect size will be calculated as follows:

$$
\delta_{\mathrm{a}}=\mu_{1}-\mu_{2} /{ } p \sigma^{2}{ }_{1}+q \sigma_{2}^{2}
$$

where $p$ and $q$ indicate the number of persons from each population group respectively. The guidelines that can be used here are as follows:

$|\delta|=0,2$ : small effect

$|\delta|=0,5:$ moderate effect

$|\delta|=0,8$ : large effect

(the absolute value of $\delta$ is given seeing that negative values can be obtained when $\mu_{1}<\mu_{2}$ ).

Only when statistically significant results (on the $1 \%$ or $5 \%$ level) are found will the corresponding effect size be calculated.

\section{RESULTS}

\subsection{Moral Behaviour Scale (MBS)}

The descriptive statistics (averages and standard deviations) for the total research group affecting the 20 items of the MBS are provided in Table 2 . The scale values range between 1 meaning "I strongly agree" to 10 meaning "I strongly disagree". 
Table 2: Averages and standard deviations of the $20 \mathrm{MBS}$ items for the total investigation group

\begin{tabular}{|c|c|c|c|}
\hline MBS-item & $\mathrm{N}$ & $\mathrm{X}$ & S \\
\hline 1. To kill a person in defence of one's own life & 328 & 4,99 & 3,58 \\
\hline 2. To have sex while unmarried & 331 & 6,57 & 3,55 \\
\hline 3. To forge a cheque & 326 & 8,82 & 2,53 \\
\hline 4. Girl's smoking cigarettes & 328 & 7,84 & 3,15 \\
\hline $\begin{array}{l}\text { 5. An industry's maintaining working conditions for } \\
\text { its workers known to be detrimental to their } \\
\text { health }\end{array}$ & 328 & 7,87 & 3,09 \\
\hline $\begin{array}{l}\text { 6. A doctor's allowing a badly deformed baby to die } \\
\text { when he could save its life but not cure its } \\
\text { deformity }\end{array}$ & 325 & 7,57 & 3,17 \\
\hline 7. To testify falsely in court when under oath & 326 & 8,71 & 2,51 \\
\hline $\begin{array}{l}\text { 8. A jury's freeing a father who has killed a man for } \\
\text { rape against his young daughter }\end{array}$ & 330 & 5,52 & 3,75 \\
\hline 9. To bootleg (copy illegally) under prohibition & 330 & 7,55 & 2,98 \\
\hline $\begin{array}{l}\text { 10. To have illicit (dishonest) sex relations after } \\
\text { marriage }\end{array}$ & 329 & 8,90 & 2,37 \\
\hline $\begin{array}{l}\text { 11. A prosperous industry's paying workers less than } \\
\text { a living wage }\end{array}$ & 328 & 8,88 & 2,41 \\
\hline $\begin{array}{l}\text { 12. A strong commercial concern's selling below cost } \\
\text { to crowd out a weaker competitor }\end{array}$ & 330 & 6,12 & 3,15 \\
\hline $\begin{array}{l}\text { 13. A student's reporting a higher grade than the one } \\
\text { earned when grading his/her own paper }\end{array}$ & 330 & 8,34 & 2,62 \\
\hline $\begin{array}{l}\text { 14. To keep the money when given too much change } \\
\text { by a shop assistant }\end{array}$ & 329 & 6,41 & 3,44 \\
\hline $\begin{array}{l}\text { 15. To copy from another's paper in a school } \\
\text { examination }\end{array}$ & 329 & 8,65 & 2,62 \\
\hline $\begin{array}{l}\text { 16. To take one's own life (assuming no near relatives } \\
\text { or dependents) }\end{array}$ & 330 & 8,59 & 2,64 \\
\hline $\begin{array}{l}\text { 17. To refuse to bear arms in a war one believes to be } \\
\text { unjust }\end{array}$ & 330 & 5,87 & 3,57 \\
\hline $\begin{array}{l}\text { 18. To advertise to cure a disease known to be } \\
\text { incurable by such a remedy }\end{array}$ & 325 & 8,14 & 3,04 \\
\hline $\begin{array}{l}\text { 19. Nation's using poison gas on civilians of one's } \\
\text { enemies }\end{array}$ & 327 & 8,76 & 2,55 \\
\hline $\begin{array}{l}\text { 20. A man deserting a girl whom he has made } \\
\text { pregnant without himself taking responsibility }\end{array}$ & 329 & 9,08 & 2,29 \\
\hline
\end{tabular}

From Table 2 it is clear that the average respondent is not in favour of the 20 hypothetical situations stated in the MBS indicating awareness for moral behaviour. 
The role of the identified biographical variables affecting the Grade 10 learners' perception of morality on the MBS will now be discussed. For this purpose the means of the vectors of all 20 dependent variables (20 items) for the different gender, culture, lifestyle, religious and sexual practices groups were compared. The Hotelling $\mathrm{T}^{2}$ test for independent groups was used for these purposes and was computed using the BMDP P3D programme (Dixon 1985). The results are shown in Table 3.

Table 3: Results of the $\mathrm{T}^{2}$ and $\mathrm{F}$ values for the comparison of the MBS vector averages for the different groups of the independent variables

\begin{tabular}{|l|l|c|c|c|l|l|}
\hline $\begin{array}{c}\text { Independent } \\
\text { variable }\end{array}$ & $\begin{array}{c}\text { Degrees of } \\
\text { freedom }\end{array}$ & $\begin{array}{c}\text { Mahalanobis } \\
D^{2}\end{array}$ & $\begin{array}{c}\text { Hotelling } \\
T^{2}\end{array}$ & $\begin{array}{c}F- \\
\text { value }\end{array}$ & $\begin{array}{c}p- \\
\text { value }\end{array}$ & $f$ \\
\hline Gender & $20 ; 319$ & 1,32 & 112,54 & 5,31 & $0,0000 * *$ & 0,61 \\
\hline Culture & $20 ; 291$ & 0,99 & 77,37 & 3,63 & $0,0000 * *$ & 0,53 \\
\hline Lifestyle & $20 ; 296$ & 0,58 & 39,26 & 1,84 & $0,0162 *$ & 0,37 \\
\hline Religion & $20 ; 283$ & 0,68 & 45,82 & 2,15 & $0,0035 * *$ & 0,41 \\
\hline $\begin{array}{l}\text { Sexual } \\
\text { practices }\end{array}$ & $20 ; 316$ & 0,73 & 50,70 & 2,39 & $0,0009 * *$ & 0,41 \\
\hline
\end{tabular}

$$
\begin{array}{ll}
* & \mathrm{p} \leq 0,05 \\
* * & \mathrm{p} \leq 0,01
\end{array}
$$

Table 3 illustrates that the calculated $\mathrm{T}^{2}$ values for four of the five independent variables are significant at the $1 \%$ level while the other independent variable is significant at the $5 \%$ level. In order to comment on the practical importance of these statistically significant results, $f$ has to be calculated. The effect size $(f)$ indicates a medium to large effect size for all five of the independent variables and consequently indicates that the results are of average to great practical value.

In order to determine which of the 20 items for the two groups' (for each biographical variable) averages differ significantly, the $\mathrm{T}^{2}$ test for independent groups was used. This was done for each of the biographical variables. Before the $t$-test results are shown, it is important to note that where differing independent variables are present (as in this case where 20 items are being used), it is preferable that the acquired $p$-value of each comparison separately be at least $0,01 / 20=$ 
0,0005 or $0,05 / 20=0,0025$ in order to differentiate on the multiple level of significance of $1 \%$ or $5 \%$ according to Shaw and Du Toit (1985).

The results obtained for each variable will now be discussed.

\section{Gender}

The analysis of the multiple level of significance comparisons utilising the $t$-test for the 20 dependent variables for gender along with the calculated effect size $(\delta)$ will be displayed in Table 4. (Only items with significant t-values are shown.)

Table 4: Averages, standard variations, $t$ and $p$ values and effect size with regards to the items for gender

\begin{tabular}{|l|c|c|c|c|c|c|c|}
\hline \multirow{2}{*}{$\begin{array}{c}\text { Dependent } \\
\text { variable }\end{array}$} & \multicolumn{2}{|c|}{ Female } & \multicolumn{2}{c|}{ Male } & $t$ & $p$ & $\delta$ \\
\cline { 2 - 6 } & $\mathrm{X}$ & $\mathrm{s}$ & $\mathrm{X}$ & $\mathrm{s}$ & & & \\
\hline Item 2 & 7,88 & 2,91 & 5,26 & 3,63 & 7,33 & $0,0000^{* *}$ & 0,80 \\
Item 9 & 8,16 & 2,60 & 6,82 & 3,24 & 4,17 & $0,0000^{* *}$ & 0,46 \\
Item 12 & 6,75 & 2,91 & 5,38 & 3,28 & 4,03 & $0,0001^{* *}$ & 0,44 \\
Item 14 & 7,05 & 3,32 & 5,66 & 3,46 & 3,73 & $0,0002 * *$ & 0,41 \\
Item 20 & 9,61 & 1,47 & 8,57 & 2,78 & 4,27 & $0,0000^{* *}$ & 0,47 \\
\hline
\end{tabular}

$$
\begin{array}{ll}
* & \mathrm{p} \leq 0,0025 \text { (multiple level of significance } 5 \% \text { level) } \\
* * & \mathrm{p} \leq 0,0005 \text { (multiple level of significance } 1 \% \text { level) }
\end{array}
$$

Table 4 reveals that the female respondents consistently achieved higher scores than the male respondents for the following items: Item 2 (To have sex while unmarried), Item 9 (To bootleg under prohibition - to copy illegally), Item 12 (A strong commercial concern's selling below cost to crowd out a weaker competitor), Item 14 (To keep the money when given too much change by a shop assistant) and Item 20 (A man deserting a girl whom he has made pregnant without himself taking responsibility). This implies that the female learners appear to be more aware of moral behaviour than the male learners.

\section{Culture}

The results for the two cultural groups (African/White) appear in Table 5. 
Table 5: Averages, standard variations, $\mathrm{t}$ and $\mathrm{p}$ values and effect size with regards to the items for culture groups

\begin{tabular}{|l|c|c|c|c|l|l|l|}
\hline \multirow{2}{*}{$\begin{array}{c}\text { Dependent } \\
\text { variable }\end{array}$} & \multicolumn{2}{|c|}{ African (Black) } & \multicolumn{2}{|c|}{ White } & \multirow{2}{*}{$t$} & \multirow{2}{*}{$\boldsymbol{\delta}$} & $\delta$ \\
\cline { 2 - 6 } & $\mathrm{X}$ & $\mathrm{s}$ & $\mathrm{X}$ & $\mathrm{s}$ & & & \\
\hline Item 1 & 5,82 & 3,78 & 3,87 & 2,99 & 5,02 & $0,0000 * *$ & 0,57 \\
Item 4 & 8,33 & 3,01 & 7,20 & 3,24 & 3,14 & $0,0017 *$ & 0,36 \\
\hline
\end{tabular}

$$
\begin{array}{ll}
* & \mathrm{p} \leq 0,0025 \text { (multiple level of significance 5\% level) } \\
* * & \mathrm{p} \leq 0,0005 \text { (multiple level of significance 1\% level) }
\end{array}
$$

Table 5 indicates that there is a statistical difference between the two cultural groups, with the white respondents achieving lower scores than the African respondents on items Item 1 (To kill a person in defence of one's own life) and Item 4 (Girl's smoking cigarettes).

\section{Lifestyle}

With regards to this biographical variable, none of the 20 items achieved a significant $t$-value at the $5 \%$ multiple level of significance and therefore no analysis was performed.

\section{Religion}

The results for the two religion groups (weekly or more/monthly or less) appear in Table 6.

Table 6: Averages, standard variations, $\mathrm{t}$ and $\mathrm{p}$ values and effect size with regards to the items for the religious groups

\begin{tabular}{|c|c|c|c|c|l|l|l|}
\hline \multirow{2}{*}{$\begin{array}{c}\text { Dependent } \\
\text { variable }\end{array}$} & \multicolumn{2}{|l|}{ Weekly or more } & Monthly or less & $t$ & \multirow{2}{*}{$p$} & $\delta$ \\
\cline { 2 - 6 } & $\mathrm{X}$ & $\mathrm{s}$ & $\mathrm{X}$ & $\mathrm{s}$ & & & \\
\hline Item 20 & 9,53 & 1,57 & 8,61 & 2,82 & 3,02 & $0,0004 * *$ & 0,45 \\
\hline
\end{tabular}

* $\quad \mathrm{p} \leq 0,0025$ (multiple level of significance 5\% level)

$* * \quad \mathrm{p} \leq 0,0005$ (multiple level of significance 1\% level)

This table demonstrates that the group of learners who practise their religion often (at least once a week) condemned the actions judged to be immoral more than did the group who did not practise their 
religion as often as indicated by responses obtained for Item 20 (A man deserting a girl whom he has made pregnant without himself taking responsibility).

Sexual practices

The results for the two sexual practices groups (yes/no) are displayed in Table 7.

Table 7: Averages, standard variations, $t$ and $p$ values and effect size with regards to the items for the sexual practices groups

\begin{tabular}{|c|c|c|c|c|l|l|l|}
\hline \multirow{2}{*}{$\begin{array}{c}\text { Dependent } \\
\text { variable }\end{array}$} & \multicolumn{2}{|c|}{ Yes } & \multicolumn{2}{c|}{ No } & $t$ & $p$ & $\delta$ \\
\cline { 2 - 5 } & $\mathrm{X}$ & $\mathrm{s}$ & $\mathrm{X}$ & $\mathrm{s}$ & & & \\
\hline Item 2 & 4,98 & 3,55 & 7,21 & 3,32 & $-5,47$ & $0,0000 * *$ & $-0,66$ \\
\hline
\end{tabular}

* $\quad \mathrm{p} \leq 0,0025$ (multiple level of significance 5\% level)

$* * \quad \mathrm{p} \leq 0,0005$ (multiple level of significance 1\% level)

A large statistical difference exists between the group that is sexually active and the group that is not sexually active. While the group of learners who are not sexually active appears to condemn premarital sex, the group of learners who report being sexually active appear ambivalent regarding pre-marital sex. This is expressed by the responses obtained for Item 2 (To have sex while unmarried).

\subsection{Morally Debatable Behaviour Scale (MDS)}

The descriptive statistics (averages and standard deviations) for the total research group affecting the 22 items of the MDS are provided in Table 8 . The scale values range between 1 meaning "never justifiable" and 10 meaning "always justifiable". 
Table 8: Averages and standard deviations for the 22 MDS items for the total investigation group

\begin{tabular}{|l|c|c|c|}
\hline \multicolumn{1}{|c|}{ MBS-item } & $\mathrm{N}$ & $\mathrm{X}$ & $\mathrm{s}$ \\
\hline 1. Claiming state benefits that you are not entitled to & 319 & 4,25 & 3,48 \\
2. Avoiding taxi fare on public transport & 330 & 4,57 & 3,54 \\
3. Cheating on tax if you have the chance & 331 & 3,95 & 3,38 \\
4. Buying something you knew was stolen & 331 & 3,61 & 3,36 \\
5. Taking and driving away a car belonging to & & & \\
someone else (joyriding) & 331 & 3,53 & 3,41 \\
6. Taking the drug marijuana or hashish & 332 & 3,76 & 3,47 \\
7. Keeping the money that you have found & 331 & 6,60 & 3,46 \\
8. Lying in your own interest & 331 & 4,73 & 3,42 \\
9. Married men or women having an affair & 330 & 3,44 & 3,41 \\
10. Sex under the legal age of consent & 329 & 4,04 & 3,46 \\
11. Someone accepting a bribe in the course of their & 330 & 3,51 & 3,06 \\
duties & 331 & 4,00 & 3,50 \\
12. Homosexuality & 331 & 3,31 & 3,07 \\
13. Prostitution & 332 & 3,90 & 3,38 \\
14. Abortion & 332 & 5,25 & 3,29 \\
15. Divorce & 331 & 4,68 & 3,35 \\
16. Fighting with the police & & & \\
17. Euthanasia (terminating the life of the incurably & 330 & 5,29 & 3,62 \\
sick) & 333 & 3,39 & 3,22 \\
18. Suicide & & & \\
19. Failing to report damage that you have done & 332 & 4,08 & 3,19 \\
accidentally to a parked vehicle & 331 & 3,18 & 3,16 \\
20. Threatening workers who refuse to join a strike & 334 & 6,50 & 3,48 \\
21. Killing in self-defence & 333 & 3,89 & 3,34 \\
22. Political assassination & & \\
\hline
\end{tabular}

From Table 8 it is evident that the majority of the responses indicate that most of the items are never justifiable. For instance, Item 20 (Threatening workers who refuse to join a strike) has the highest rating (3.18) of being regarded as an unjustifiable act. Items 13 (Prostitution), 18 (Suicide), and 9 (Married men or women having an affair) also have a high incidence of being regarded as never being justifiable. While the responses indicate that most of the situations are never justifiable, the items adjudged to be justifiable never obtain the same degree of rating. Item 7 (Keeping the money that you have found) 
achieves the highest rating (6.60). From the table then, it can be concluded that the average respondent does not feel that the 22 hypothetical situations stated in the MDS can be justifiable. Once again, this would imply an awareness of moral behaviour.

The role of the identified biographical variables affecting the Grade 10 learners' perception of morality on the MDS will be investigated next. For this purpose the means of the vectors of all 22 dependent variables for the different gender, culture, lifestyle, religious and sexual practices groups will be compared. The Hotelling $\mathrm{T}^{2}$ test for independent groups is used for these purposes and it is computed using the BMDP P3D programme (Dixon 1985). The results appear in Table 9.

Table 9: Results of the $\mathrm{T}^{2}$ and $\mathrm{F}$ values for the comparison of the MDS vector averages for the different groups of the independent variables

\begin{tabular}{|l|l|c|c|c|c|c|}
\hline $\begin{array}{c}\text { Independent } \\
\text { variable }\end{array}$ & $\begin{array}{c}\text { Degrees of } \\
\text { freedom }\end{array}$ & $\begin{array}{c}\text { Mahalanobis } \\
D^{2}\end{array}$ & $\begin{array}{c}\text { Hotelling } \\
T^{2}\end{array}$ & $\begin{array}{c}F- \\
\text { value }\end{array}$ & $\begin{array}{c}p- \\
\text { value }\end{array}$ & $f$ \\
\hline Gender & $22 ; 317$ & 1,04 & 87,95 & 3,75 & $0,0000 * *$ & 0,54 \\
\hline Culture & $22 ; 289$ & 0,79 & 61,38 & 2,60 & $0,0002 * *$ & 0,47 \\
\hline Lifestyle & $22 ; 294$ & 0,43 & 29,21 & 1,24 & 0,2133 & - \\
\hline Religion & $22 ; 281$ & 0,47 & 31,52 & 1,33 & 0,1486 & - \\
\hline $\begin{array}{l}\text { Sexual } \\
\text { practices }\end{array}$ & $22 ; 314$ & 0,75 & 52,44 & 2,23 & $0,0014 * *$ & 0,42 \\
\hline
\end{tabular}

$$
\begin{array}{ll}
* & \mathrm{p} \leq 0,05 \\
* * & \mathrm{p} \leq 0,01
\end{array}
$$

Table 9 shows that the calculated $\mathrm{T}^{2}$ values for three of the five independent variables, namely gender, culture and sexual practices are significant at the $1 \%$ level. The corresponding f-values indicate a large effect size and consequently indicate that the results are of great practical value.

In order to determine which of the 22 items for the two groups' (for each biographical variable) averages differ significantly, the $\mathrm{T}^{2}$ test for independent groups is used. This is done for each of the biographical variables. 
The results obtained for each variable will now be discussed.

\section{Gender}

The analysis of the multiple level of significance comparisons utilising the $t$-test for the 22 dependent variables for gender is now analysed. The results, along with the calculated effect size $(\delta)$ are illustrated in Table 10.

Table 10: Averages, standard variations, $t$ and $p$ values and effect size with regards to the items for gender

\begin{tabular}{|l|c|c|c|c|c|c|c|}
\hline \multirow{2}{*}{$\begin{array}{c}\text { Dependent } \\
\text { variable }\end{array}$} & \multicolumn{2}{|c|}{ Female } & \multicolumn{2}{c|}{ Male } & \multirow{2}{*}{$t$} & \multirow{2}{*}{$\delta$} & $\delta$ \\
\cline { 2 - 5 } & $\mathrm{X}$ & $\mathrm{s}$ & $\mathrm{X}$ & $\mathrm{s}$ & & & \\
\hline Item 7 & 5,70 & 3,41 & 7,43 & 3,31 & $-4,72$ & $0,0000 * *$ & $-0,51$ \\
Item 10 & 3,37 & 3,24 & 4,97 & 3,57 & $-4,28$ & $0,0000 * *$ & $-0,47$ \\
Item 12 & 4,63 & 3,60 & 3,31 & 3,23 & 3,54 & $0,0005 * *$ & 0,39 \\
Item 19 & 3,64 & 3,02 & 4,68 & 3,32 & $-3,01$ & $0,0023 *$ & $-0,33$ \\
Item 21 & 5,84 & 3,52 & 7,27 & 3,26 & $-3,89$ & $0,0001 * *$ & $-0,42$ \\
\hline
\end{tabular}

$$
\begin{array}{ll}
* \quad \mathrm{p} \leq 0,0025 \text { (multiple level of significance 5\% level) } \\
* * \quad \mathrm{p} \leq 0,0005 \text { (multiple level of significance 1\% level) }
\end{array}
$$

Table 10 indicates that the male respondents consistently score higher on the MDS for all the items barring the item relating to homosexuality. These items included Item 7 (Keeping the money that you have found), Item 10 (Sex under the legal age of consent), Item 12 (Homosexuality), Item 19 (Failing to report damage that you have done accidentally to a parked vehicle) and Item 21 (Killing in selfdefence). This shows that the male learners find it harder to justify homosexuality than the female learners, thus demonstrating a stronger disapproval.

\section{Culture}

The results obtained for the two culture groups (African/White) are illustrated in Table 11. 
Table 11: Averages, standard variations, $\mathrm{t}$ and $\mathrm{p}$ values and effect size with regards to the items for the cultural groups

\begin{tabular}{|l|c|c|c|c|l|l|l|}
\hline \multirow{2}{*}{$\begin{array}{c}\text { Dependent } \\
\text { variable }\end{array}$} & \multicolumn{2}{|c|}{ African (Black) } & \multicolumn{2}{|c|}{ White } & \multirow{2}{*}{$p$} & $\delta$ \\
\cline { 2 - 5 } & $\mathrm{X}$ & $\mathrm{s}$ & $\mathrm{X}$ & $\mathrm{s}$ & & & \\
\hline Item 9 & 4,14 & 3,64 & 2,84 & 3,07 & 3,38 & $0,0008^{*}$ & 0,38 \\
Item 16 & 5,28 & 3,56 & 4,13 & 2,97 & 3,08 & $0,0022 *$ & 0,35 \\
Item 20 & 3,82 & 3,38 & 2,50 & 2,69 & 3,84 & $0,0002 * *$ & 0,43 \\
\hline
\end{tabular}

* $\quad \mathrm{p} \leq 0,0025$ (multiple level of significance $5 \%$ level)

** $\quad \mathrm{p} \leq 0,0005$ (multiple level of significance $1 \%$ level)

It is clear from the table that the white learners tend towards a lower average than the African learners for these three items: Item 9 (Married men or women having an affair), Item 16 (Fighting with the police) and Item 20 (Threatening workers who refuse to join a strike). This trend could indicate cultural influences and differences in perceptions of morality, e.g. the degree to which extramarital affairs are thought to be wrong or unjustifiable.

Lifestyle

None of the 20 items achieved a significant $t$-value at the $5 \%$ level of significance and therefore no analysis was performed.

Religion

No analysis was performed as none of the 20 items achieved a significant $t$-value at the $5 \%$ multiple level of significance.

Sexual practices

The results for the two sexual practice groups (yes/no) are shown in Table 12. 
Table 12: Averages, standard variations, $t$ and $p$ values and effect size with regards to the items for sexual practices groups

\begin{tabular}{|c|c|c|c|c|c|c|c|}
\hline \multirow{2}{*}{$\begin{array}{c}\text { Dependent } \\
\text { variable }\end{array}$} & \multicolumn{2}{|c|}{ Yes } & \multicolumn{2}{|c|}{ No } & \multirow[t]{2}{*}{$t$} & \multirow[t]{2}{*}{$p$} & \multirow[t]{2}{*}{$\delta$} \\
\hline & $\mathrm{X}$ & s & $\mathrm{X}$ & s & & & \\
\hline Item 7 & 7,60 & 3,27 & 6,14 & 3,47 & 3,62 & $0,0004 * *$ & 0,43 \\
\hline Item 9 & 4,53 & 3,83 & 3,09 & 3,21 & 3,25 & $0,014^{*}$ & 0,42 \\
\hline Item 10 & 5,39 & 3,71 & 3,70 & 3,30 & 3,86 & $0,0002 * *$ & 0,49 \\
\hline Item 11 & 4,48 & 3,54 & 3,14 & 2,80 & 3,33 & $0,0011^{*}$ & 0,45 \\
\hline
\end{tabular}

$$
\begin{array}{ll}
* & \mathrm{p} \leq 0,0025 \text { (multiple level of significance 5\% level) } \\
* * & \mathrm{p} \leq 0,0005 \text { (multiple level of significance 1\% level) }
\end{array}
$$

The items in Table 12 highlight a statistical difference in significance for the averages for the group that is not sexually active. These items are Item 7 (Keeping the money that you have found), Item 9 (Married men or women having an affair), Item 10 (Sex under the legal age of consent), and Item 11(Someone accepting a bribe in the course of their duties). When the effect size is investigated, it is apparent that all the items exhibit a medium effect size. This result has average practical value.

\section{DISCUSSION}

A core finding of this study was that the female learner's responses point towards a higher level of morality than the male learners do. This result is in keeping with findings by authors such as Eisenberg et al. (1989), and Eisenberg et al. (1995) who found that adolescent girls express a higher level of moral reasoning than adolescent boys. The reason for this is unclear. Gustavo et al. (1996) and Gilligan (1982) believe that this is due to the fact that gender-specific socialisation processes may lead to gender differences in moral reasoning, although this phenomenon may be more evident in younger adolescents (Eisenberg et al. 1991).

This study also found cultural differences with regards to morality. Smith and Parekh (1996) found cross-cultural differences in morality. This may be as a result of different expectations for behaviour, attitudes, and emotional expression according to Kawanishi (1995) and 
Pittman et al. (1995). Furthermore, differences in cultural norms and level and quality of education may all influence the perceptions of morality in different cultural groups (Dawes 1994). A more likely explanation may be that of Burman (1986) who states that lack of parental involvement due to (distant) work commitments may negatively affect moral development. Many adolescents return to empty homes because their parents are working. As a result they have little contact with their parents and thus little moral instruction.

Frequency of religious practices was found to have an influence on moral expression. Beard (1988) found that religion and degree of religious devotion had an influence on morality. The "weekly or more" religion group obtained a higher average than the "monthly or less" religion group for the item. It is apparent that the learners who practise their religion more frequently tend to be more moral in their thinking, or are more judgemental of immoral acts. It is evident that regular religious instruction has a positive influence on moral development and expression. This may be due to the fact that religious instruction is synonymous with moral instruction. The differences between the "monthly or more" and the "monthly or less" groups was however not as great as one might expect to find. The frequency of religious practice does not appear to influence the level of morality to a great extent.

While Wilson and Ramphele (1989) state that socio-economic status influences moral behaviour, it was not found to be statistically significant in this study. This may be due to the fact that many of the learners reported that they felt they were not better or worse off than the average South African adolescent. From the schools tested, it may be assumed that the majority of the learners come from middle class households and therefore, lifestyle is not a significant variable.

With young South Africans under the age of 15 years old making up more than $40 \%$ of the population (Love Life Survey 2001), this study is indeed relevant to today's youth. The statistics obtained through the course of this study correlate strongly to those obtained in the 2001 National Survey of South African Youth which was administered to 2204 South African youth, nation wide (Henry J. Kaiser Family foundation, 2002). The target population of the study was 12 
to 17 year-olds. The 2001 National Survey of South African Youth found that only $29 \%$ of all youth surveyed between the ages of 12 and 17 were sexually active. Of all the respondents in this study, $29,1 \%$ reported being sexually active. This gives an indication that the results obtained in this study appear to be reliable. The learners who reported being sexually active consistently obtained lower results on the morality questionnaires than the group of learners who are not yet sexually active. It is interesting to note that while the group who is not yet sexually active is very sure of their moral persuasions; the group who is sexually active appears to be ambivalent towards issues such as premarital sex. This implies that those who are sexually active do themselves not fully condone their own actions. It also implies that casual sex may not be as socially accepted among the youth as is thought to be the case.

\section{CONCLUSION}

It is clear from the findings of this study that the variables that have the greatest bearing on morality are gender, culture, religion and sexual experience. While lifestyle may play an important role in the development of morality, the findings from this survey did not indicate it to be as important as the abovementioned variables. The female learners consistently achieved higher levels of morality on both questionnaires than the male learners did. Furthermore, the white learners emerged with higher levels of morality than the African learners on both questionnaires did. The study also indicated that past sexual experience has an effect on the perception and expression of morality.

As with any study of this nature, many problems are evident. The first major problem that is apparent when investigating people's attitudes is that there is no way of knowing whether the responses given are indeed congruent with behaviour in everyday life. Respondents could indicate a possible action or behaviour given a specific hypothetical situation, but it is impossible to know whether or not the respondent would in deed behave as indicated in reality.

Another problem encountered is that the questionnaires were only administered in English. For many of the respondents English is a 
second or third language. In order to compensate for any possible misunderstandings, each question was explained making use of everyday examples the learners could understand. No standardised explanations were given and varied between groups being tested. Despite these efforts, being tested in a second or third language may impact on the reliability of the results obtained. In addition to this, the measuring instruments used have not been standardised for the South African population. This could affect the result's validity and reliability.

Furthermore, the sample size may not be large enough to be representative of the learners in the Free State. The sample also only consists of Grade 10 learners and as such the results cannot be generalised to all learners. In addition, the fact that this study was only conducted on urban learners in the Free State makes it difficult to determine whether these results are truly representative of the nation's youth. It may be argued that the youth from urban areas may be more or less conservative than adolescents from other provinces or from rural areas in the country respectively.

Another shortcoming of this study is that it does not look at differences within cultural groups. For example, differences between English and Afrikaans learners were not investigated. There are also differences between black ethnic groups such as Zulu, Tswana and Xhosa, which were not investigated.

Apart from these problems, the nature of the questions also brings the validity of the responses into dispute. Some of the questions are of a sensitive nature, e.g., questions regarding sexual experience. Respondents may not be completely honest when answering these questions for many reasons, and therefore, the accuracy of the results may be questioned.

Against this background then, this study should be seen as being explorative in nature.

In order to counter the above-mentioned problems, it is recommended that a more encompassing study be performed. The study would have to incorporate learners from more provinces, as well as from both rural and urban areas. The sample size would also have to be increased. Measuring instruments would have to be standardised 
and the learners should preferably be able to complete the questionnaires in their first language.

Furthermore, it may be possible to analyse the results obtained in this study in order to address specific moral issues in an attempt to enhance both moral awareness and moral behaviour. Beard (1988) rightly states that it is possible to stimulate the development of moral reasoning. Maqsud (1982) and Combrink (2002) further contends that it seems possible to promote moral development in the classroom. In this regard Blatt and Kohlberg (1973:51) state that:

If brief periods of classroom discussion can have a substantial effect on moral development, a pervasive, enduring and psychologically sound concern for the school's influence upon moral development should have a much deeper and positive effect.

This is encouraging. School programmes designed to create moral awareness can indeed be effective. Since school counsellors are trained to deal with problems of learners and their families, they are best qualified to teach the importance of values and can lead in the design and implementation of morality education (Rayburn 2004). These programmes need not only take place in school though. Greater involvement in religious and church activities could also help to create a greater moral awareness. Mixed gender and racial groups could also lead to a greater moral awareness through interaction and discussion thus resulting in an improvement in morality.

Without a doubt, the issue of morality is indeed contentious and controversial. And while we may argue its origin, nature and influence, morality is as important now as it ever was, if not more so. For this reason then, morality in South Africa needs to be further investigated. 


\section{BIBLIOGRAPHY}

Address by the Deputy President Jacob Zuma to the Moral Regeneration Movement National Consultative Meeting, Johannesburg, 23 November 2001. [Online.] Retrieved from the World Wide Web on 24 February 2002: <http://www.gov.co.za/speeches/ index.html\#deputy > [2002, 24 February.]

BEARD P N G

1988. Relevant factors related to the effects of intervention on moral development in South African youth. Suid-Afrikaanse Tydskrif vir Opvoedkunde 8(4):298-302.

\section{BlatT M \& KOHLBERG L}

1973. The effects of moral classroom discussion upon children's level of moral judgement. Harvard University: Moral Education and Research Foundation.

\section{BRANCH W T}

2000. Supporting the moral development of medical students. Journal of General Internal Medicine 15:503-508.

\section{BURMAN S}

1986. The concept of childhood in South Africa: an introduction. In: S. Burman \& P. Reynolds (eds.), Growing up in a divided society (Johannesburg: Ravan Press), pp. 1-15.

\section{Bush C A, Mullis R L \& Mullis A K}

2000. Differences in empathy between offender and non-offender youth. Journal of Youth and Adolescence 26:467-478.

Carlo G, Fabes R A, Laible D \& Kupanoff K

1999. Early adolescence and prosocial/moral behaviour. I: The role of the individual process. Journal of Early Adolescence 19(1):5-16.

\section{COMBrink A}

2002. Values and norms in education. NUE Comment 6 (1):14-17.

DAWES A

1994. The effects of political violence on sociomoral reasoning and conduct. In: A. Dawes \& D. Donald (eds.), Childhood and adversity: psychological perspectives from South African research (Cape Town: David Philips), pp. 177-199.

DIXON W J

1985. Biomedical computer programs. Berkeley: University of California Press.

\section{DUNCAN G A}

2002. A place in the sun? The role of the church in moral renewal and social transformation. Verbum et Ecclesia 23(2):333-342.

\section{EISENBERG N}

2000. Emotion, regulation, and moral development. Annual Review of Psychology 51:665-697.

1986. Altruistic emotion, cognition and behaviour. Hillsdale N.J.: Erlbaum. 


\section{Eisenberg N, Carlo G, Murphy B \& Van Court P}

1995. Prosocial development in late adolescence: a longitudinal study. Child Development 66:1179-1197.

\section{Eisenberg N, Fabes R \& SHea C}

1989. Gender differences in empathy and prosocial moral reasoning: empirical investigations. In: M.M. Brabeck (ed.), Who cares? Theory, research, and educational implications of the ethic of care (New York: Praeger), pp. 127-143.

Eisenberg N, Miller P A, Shell R, McNalley S \& Shea C 1991. Prosocial development in adolescence: a longitudinal study. Developmental Psychology 27:849-857.

\section{EMERSON M O}

1996. Through tinted glasses: religion, worldviews, and abortion attitudes. Journal for the Scientific Study of Religion 35(1):41-55.

\section{GiLligan C}

1982. In a different voice: psychological theory and women's development. Cambridge Ma.: Harvard University.

\section{Gustavo C, Koller S H, Eisenberg N, Da Silva M S \& Frohlich C B}

1996. A cross-national study on the relations among prosocial moral reasoning, gender role orientation, and prosocial behaviors. Developmental Psychology 32(2): 231-240.

\section{Henry J Kaiser Family Foundation}

2002. Selected findings from a forthcoming report: the 2001 National survey of South African Youth. Parklands: Colorpress.

\section{Holmes G R, Hall H S, Sakano Y, Cautela J \& Holmes G L} 1991. Comparison of factor-analyzed adolescent reinforcement survey schedule (ARSS) responses from Japanese and American adolescents. Journal of Clinical Psychology 47:749-755.

\section{JENSEN L A}

1997. Different worldviews, different morals: America's culture war divide. Human Development 40:325-344.

\section{Judy B \& NeLson E S}

2000. Relationship between parents, peers, morality and theft in an adolescent sample. High School Journal 83:31-42.

\section{KAWANISHI Y}

1995. The effects of culture on beliefs about stress and coping: causal attribution of Anglo-American and Japanese person. Journal of Contemporary Psychotherapy 25:49-60.

\section{KOHLBERG L}

1985. The psychology of moral development. San Francisco: Harper \& Row. 


\section{Levine C G, Pakvis P \& Higgins-D’Alessandro A}

2000. Ego and moral development in university contexts: the value of consistency thesis extended. Journal of Adolescent Research 15:482-503.

\section{LoveLife \& Henry J Kaiser Family Foundation}

2001. Hot prospects and cold fats: portrait of young South Africa. Parklands: Colorpress.

\section{MAQSUD M}

1982. Effects of Nigerian children's group discussion on their moral development. Journal of Moral Education 1:181-187.

\section{MYYRY L \& HELKAMA K}

2001. University student's value priorities and emotional empathy. Educational Psychology 21:25-40.

\section{Pittman J, Gallios C I, Wawaki S \& Kroonenberg P} 1995. Australian and Japanese concepts of expressive behavior. Journal of Crosscultural Psychology 26:451-473.

\section{RAYBURN C}

2004). Assessing students for morality education: a new role for school counselors. Professional School Counseling 7(5):356-363.

\section{Robinson J P, SHAVER P R \& WRIGHTMAN L S} 1991. Measures of personality and social psychological attitudes (Vol. 1). San Diego: Academic Press.

\section{SCHWARTZ S H \& HUISMANS S} 1995. Value priority and religiosity in four Western religions. Social Psychology Quarterly 58:88-107.

\section{SHAW T M \& Du TOIT S H C} 1985. Causal relationships in longitudinal data. Research Report WS-33. Pretoria: Human Sciences Research Council.

\section{SHeLton C M \& MCAdams D P}

1990. In search of an everyday morality: the development of a measure. Adolescence 25:923-943.

\section{SMITH K \& PAREKH A}

1996. A cross-sectional study of moral development in the South African context. Psychological reports 78:85-859.

\section{STERPONI L}

2003. Account episodes in family discourse: the making of morality in everyday interaction. Discourse Studies 5(1):79-101.

\section{STEYN H S}

1999. Praktiese beduidendheid: die gebruik van effekgroottes. Potchefstroom: Publikasiebeheerkomitee, PU vir CHO. 


\section{TABACHNICK B \& Fidell L S}

1989. Using multivariate statistics. $2^{\text {nd }}$ ed. New York: Harper \& Row.

\section{VAN DER VEN J A}

2002. The information of churches as moral communities. Praktiese Teologie in Suid-Afrika 17(2):102-128.

\section{VANDER ZANDER J W}

1989. Human development. $4^{\text {th }}$ ed. New York: Knorpf.

\section{WALKER L J}

1991. Sex differences in moral reasoning. In: W.M. Kurtines \& J.L. Gerwitz (eds.), Handbook of moral behavior and development: Vol. 2. Research (Hillsdale, HJ: Erlbaum), pp. 333-364.

\section{White F A \& MATAWIE K M}

2004. Parental morality and family processes as predictors of adolescent morality. Journal of Child and Family Studies 13(2):219-234.

WILSON F \& RAMPHELE M 1989. Children in South Africa, a crisis in caring. In: J. Hughes \& D. Harland (eds.), Children on the front line (New York: UNICEF), pp. 36-43.

Keywords

Morality

Adolescents

Cross-cultural
Trefwoorde

Moraliteit

Adolessente

Kruis-kultureel 